\section{Über die Abhängigkeit der Fremdlöschung von der Konzentration des lumineszierenden Stoffes bei Lösungen}

\section{SzöLlösy}

Institut für Experimentalphysik der Universität Szeged, Ungarn

(Z. Naturforschg. 20 a, 163 [1965] ; eingegangen am 12. November 1964)

Die mit KJ ausgelöschte Fluoreszenz wässeriger Fluoresceinlösungen verschiedener Konzentrationen wurde von Sweschnikow ${ }^{1}$ untersucht, und es wurde eine Abhängigkeit der Ausbeute von der Konzentration des Farbstoffes und des Löschstoffes gefunden. Dieses Ergebnis, das später in der Literatur mehrmals zitiert wurde $^{2}$, ist deshalb wichtig, weil es zur Prüfung der Gültigkeit verschiedener Löschformeln bzw. zur Deutung dieser Abhängigkeit dienen kann. Stepanow gibt z. B. eine naheliegende Erklärung an ${ }^{2}$ : wegen der Abhängigkeit der in den verschiedenen Löschtheorien vorkommenden Löschkonstanten von der Fluoreszenzausbeute der ungelöschten Lösungen könnte die Abhängigkeit der Ausbeute von der Farbstoffkonzentration mit der Konzentrationsabhängigkeit der Abklingzeit gedeutet werden. In diesem Falle sollten aber Ausbeute und Abklingzeit ähnliche Konzentrationsabhängigkeiten zeigen.

Die Abklingzeit der Fluoreszenz von ungelöschten wässerigen Fluoresceinlösungen als Funktion der Farbstoffkonzentration wurde von $\mathrm{S}_{\text {chmillen }}{ }^{3}$ angegeben. Die Abklingzeiten $\tau$ nach Schmillen (mit $\times$ bezeichnet) und die reziproken relativen Ausbeuten $\eta_{0} / \eta$ nach Sweschnikow ${ }^{1}$ (bei einer KJ-Konzentration von $0,4 \mathrm{~g}$ pro $\mathrm{cm}^{3}$; mit $\bullet$ bezeichnet) sind in Abb. 1 wiedergegeben. Es ist ersichtlich, daß die mit einer visuellen Methode erhaltenen $\eta_{0} / \eta$-Werte wirklich einen ähnlichen Gang aufweisen.

Neuerdings wurde die Ausbeute desselben Systems mit einer schon früher von Budó und Mitarbeitern ${ }^{4}$ ausführlicher publizierten objektiven Methode nochmals ausgemessen ${ }^{5}$. Wenn man die Meßpunkte der auf Sekundärfluoreszenz korrigierten, wahren $\eta_{0} / \eta$-Werte des Verfassers ${ }^{5}$ (bei einer KJ-Konzentration von $10^{-2}$ $\mathrm{Mol} / \mathrm{l}$ ) in Abb. 1 aufträgt (mit $\circ$ bezeichnet), so erhält man keine ausgeprägte Abhängigkeit der relativen Aus-

1 B. Sweschnikow, Acta Physicochim. USSR 4, 453 [1936].

2 B. I. Stepanow, Lum. Slozh. Mol. Akad. BSSR 1955, S. 248.

3 A. Schmillen, Z. Angew. Phys. 6, 260 [1954].

4 A. Budó, J. Dombi u. L. Szöllösy, Acta Phys. Chem. Szeged 2, 18 [1956].

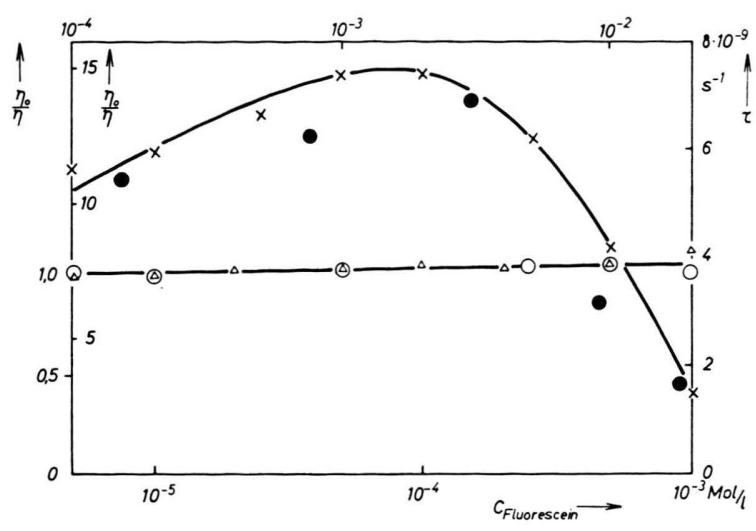

Abb. 1. Abklingzeiten $\tau$ und Fluoreszenzausbeuten $\eta_{0} / \eta$ wäßriger Fluoresceinlösungen. Die untere Abszisse und die äußere Ordinate gehören zu den Meßpunkten $\bigcirc, \triangle$; die obere $\mathrm{Ab}$ szisse und die innere Ordinate gehören zu den mit $\bullet$ und $X$ bezeichneten Meßpunkten.

beute von der Fluoresceinkonzentration (wenigstens in dem untersuchten Konzentrationsbereich). Budó und Szalay ${ }^{6}$ haben gezeigt, daß das Ansteigen der $\tau$-Kurve auf die Sekundärfluoreszenz zurückgeführt werden kann und die wahre Abklingzeit in einem weiten Konzentrationsbereich keine Abhängigkeit von der Fluorescein-Konzentration aufweist (mit $\triangle$ bezeichnet). Wie aus Abb. 1 leicht zu ersehen ist, fallen nicht nur die unmittelbar gemessenen zwei scheinbaren Größen von $\eta_{0} / \eta$ und $\tau$ praktisch zusammen, sondern auch die auf Sekundärfluoreszenz korrigierten wahren Werte.

Diese Feststellungen scheinen auch durch die für Trypaflavin-Lösungen erhaltenen Ergebnisse unterstützt. Die wahre Fluoreszenzausbeute von mit Hydrochinon ausgelöschten äthanolischen Trypaflavin-Lösungen scheint von der Farbstoffkonzentration praktisch unabhängig zu sein, die scheinbare Ausbeute zeigt aber einen ähnlichen Gang, wie die Änderung der von Schmillen ${ }^{7}$ angegebenen $\tau$-Werte.

Da die sich aus den Messungen ergebende Abhängigkeit der Ausbeute von der Farbstoffkonzentration nach Berücksichtigung der Sekundärlumineszenz verschwindet, erscheint eine molekular-physikalische Erklärung unserer Ansicht nach nicht notwendig.

5 L. Szöllösy, Acta Phys. Chem. Szeged 8, 8 [1962].

6 A. Budó u. L. Szalay, Z. Naturforschg. 18 a, 90 [1963].

7 A. Schmillen, Z. Phys. 135, 294 [1953]. 